\title{
A Rare Middle Ear Cholesteatoma Complication behind Painless Swelling of the Temporozygomatic Region
}

\author{
Caterina Bruzzi ${ }^{1}$, Maurizio Negri ${ }^{1}$ Manuele Casale ${ }^{2 *}$, Valeria Frari², Fabrizio Salvinelli², \\ Stefano Galli1 \\ ${ }^{1}$ ENT Unit, Neuroscience Department, Carpi Hospital, Carpi, Italy \\ ${ }^{2}$ Department of Otolaryngology, Campus Bio-Medico University, School of Medicine, Rome, Italy \\ Email: ${ }^{*}$ m.casale@unicampus.it
}

Received 5 June 2014; revised 4 July 2014; accepted 3 August 2014

Copyright (C) 2014 by authors and Scientific Research Publishing Inc.

This work is licensed under the Creative Commons Attribution International License (CC BY).

http://creativecommons.org/licenses/by/4.0/

(c) (i) Open Access

\begin{abstract}
Complications of middle ear cholesteatoma are well described in the literature and are classified into two major categories: intratemporal and intracranial. They are due either to infection or to local extension of the disease and consequent invasion of surrounding tissues. We describe an unusual case of an extratemporal complication in a young woman who was treated at our service. Ten years previously she had undergone canal-wall-down tympanoplasty that did not achieve complete control of the disease. At this admission, the patient was found to have peculiar extension of the recurrent cholesteatoma into the temporozygomatic area. She underwent tympanoplasty of the canal wall using a targeted surgical technique. We resected the recurrent cholesteatoma en bloc without damaging the facial nerve despite extension of the mass to the ear and face. Follow-up was performed each year for 7 years without evidence of recurrence. Cholesteatomas are highly osteolytic, and extension of any residual cholesteatoma is unpredictable. Cholesteatoma of the middle ear requires a careful surgical approach to avoid complications, maintaining awareness of its possible extension into surrounding structures.
\end{abstract}

\section{Keywords}

Cholesteatoma Complications, Canal-Wall-Down Tympanoplasty, Residual Cholesteatoma

\section{Introduction}

Middle ear cholesteatoma complications are caused by local extension of the disease and consequent invasion

\footnotetext{
*Corresponding author.
}

How to cite this paper: Bruzzi, C., Negri, M., Casale, M., Frari, V., Salvinelli, F. and Galli, S. (2014) A Rare Middle Ear Cholesteatoma Complication behind Painless Swelling of the Temporozygomatic Region. Neuroscience \& Medicine, 5, 196-199. http://dx.doi.org/10.4236/nm.2014.54022 
into surrounding tissue. The effects of this invasion may include bone erosion and infection. Antibiotics and improved surgical techniques have led to fewer infective complications.

The complications of middle ear cholesteatoma can be classified into two major categories: intracranial and intratemporal. Intracranial complications include meningitis, brain abscess, multiple abscesses, sigmoid sinus thrombosis, hydrocephalus, and meningoencephalic hernia. Most of these complications require timely surgical treatment. Intratemporal complications are typically tympano-ossicular chain disruption, labyrinthine fistula, mastoid abscesses (Bezold, mastoid subperiosteal, zygomatic) [1], facial palsy or paralysis, and apicitis pyramidalis (Gradenigo's syndrome). The zygomatic abscess is the rarest mastoid abscess, requiring early radical mastoidectomy to eradicate the source of the infection [2]. When the cells of the pneumatic system of the zygomatic root and/or the foot of the temporal bone squama are well developed, cholesteatoma may reach these cells via temporozygomatic extension above the auricular pavilion and in the lower palpebral area [2] [3]. The complications are often consequent to middle ear surgery. In these cases, extension of recurrent/residual middle ear cholesteatoma is unpredictable.

\section{Case Presentation}

A young woman was admitted to our unit in 2005 complaining about a conspicuous but painless swelling in the right temporozygomatic region that had grown slowly over the preceding year. It had an elastic consistency and was partially mobile relative to its surroundings. She suffered right hearing loss but no dizziness. Ten years previously, she had undergone canal-wall-down tympanoplasty for a cholesteatoma of the right ear at another institution.

At the present admission, she underwent audiometric testing, high-resolution computed tomography (CT), and magnetic resonance imaging (MRI). Audiometry showed right conductive hearing loss of the middle entity and left normoacusia. Her CT images showed a conspicuous capsulated mass $(4 \times 6 \mathrm{~cm})$ with isointensity to soft tissues without contrast enhancement. The mass was invading the right small eardrum cavity, growing from the attic region to the zygomatic process. The CT scans were useful for evaluating the limits of the previous surgery, determining if there were any complications (there was no erosion of the major structures, labyrinthine fistula, or tegmen erosion), and for planning further surgery.

On MRI, the swelling was suspected to be a cholesteatoma because of the presence of high signal intensity on T2-weighted sequences and isosignaling on T1-weighted sequences with no enhancement after injection of gadolinium (Figure 1). For this particular condition, MRI was necessary to plan the en bloc resection, and it contributed to the differential diagnosis [4] [5].

The prior canal-wall-down tympanoplasty was reviewed, and the previous meatoplasty was found to be satisfactory. The current incision was devised to eradicate the peculiarly extended cholesteatoma en bloc. It was performed in the retroauricular sulcus and was enlarged into the upper anterior temporal region to avoid the temporozygomatic branches of the facial nerve. We observed a small healthy eardrum and a $4 \times 6 \mathrm{~cm}$ mass growing from the anterior attic region (residual attical cholesteatoma) through the soft tissues of the temporozygomatic region. The mass was removed en bloc (Figure 2). There was no need for a second look. Histopathology confirmed that it was a cholesteatoma.

\section{Conclusions}

The postoperative course was unremarkable. There were no vestibular symptoms and no facial nerve damage. Her hearing was unchanged after surgery. The patient was followed up postoperatively with CT scans and audiometric tests at 1 and 7 years.

Extension of cholesteatoma through soft tissues of the temporozygomatic region above the ear occurs infrequently. Our patient was managed successfully with adequate ad hoc surgery.

\section{Competing Interests}

The authors declare that they have no competing interests.

\section{Acknowledgements}

We thank Leona Bassein and Daniele Benincasa for revising the English and contributing to the organization of 


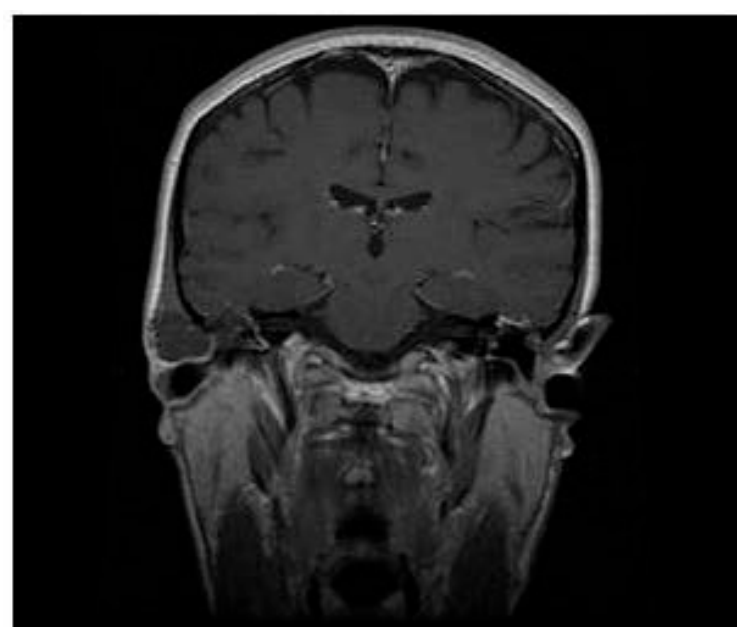

(a)

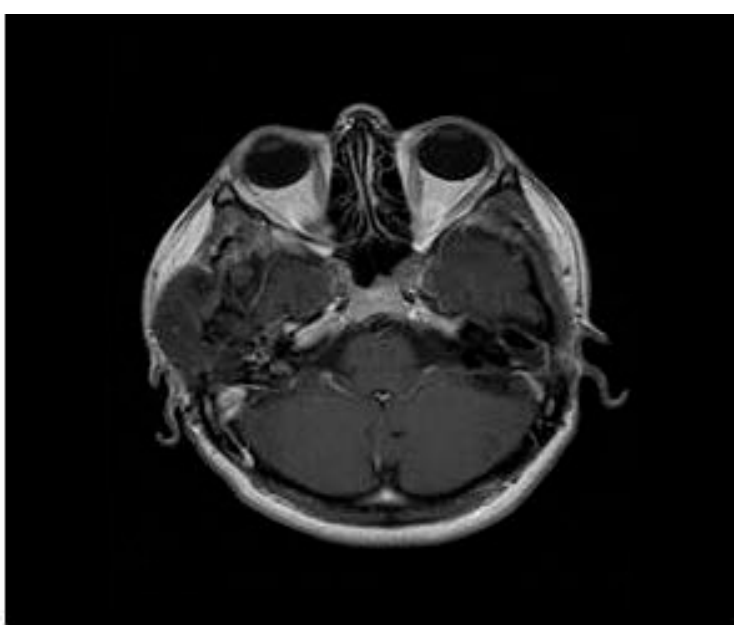

(b)

Figure 1. Coronal and axial MRI T1-weighted image shows the limits and extension of the cholesteatoma.

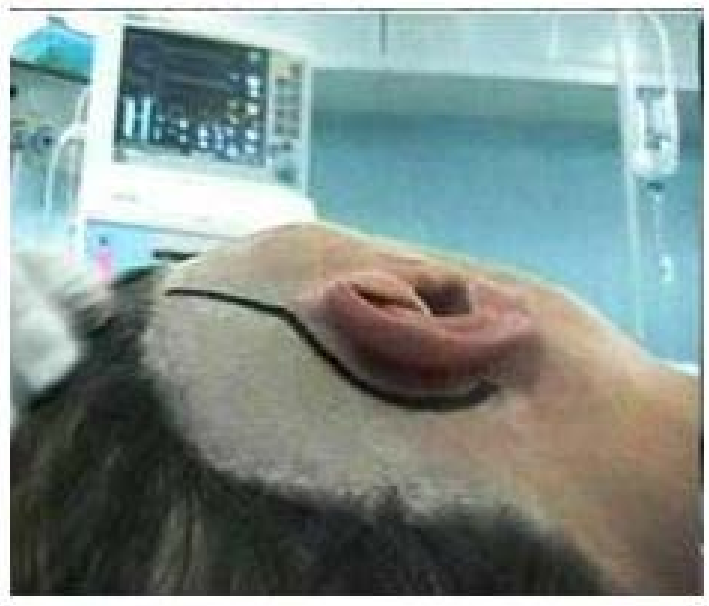

(a)

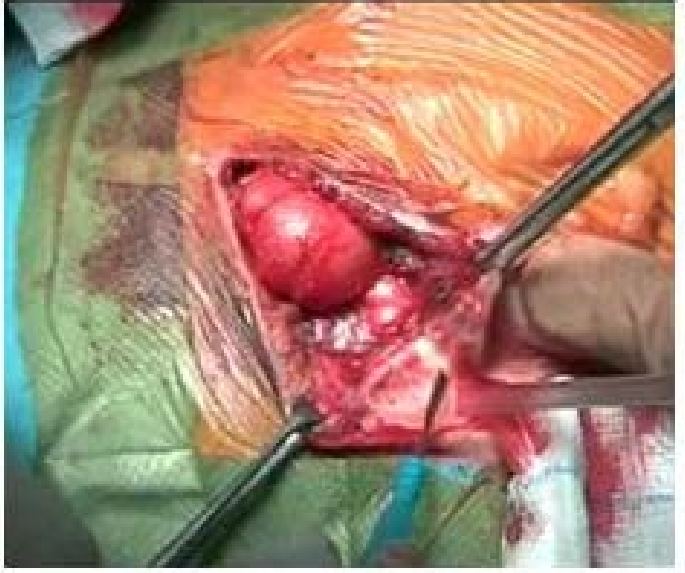

(b)

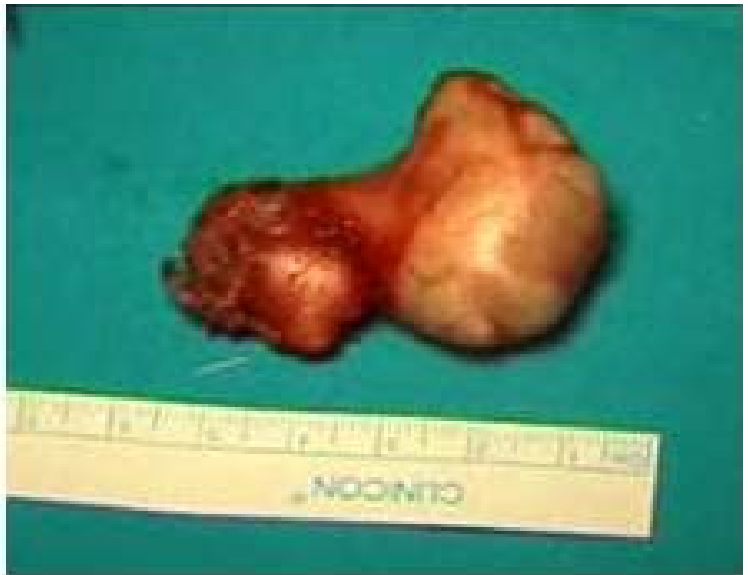

(c)

Figure 2. Incision is in the retroauricular sulcus and enlarged in the upper anterior temporal region to avoid the temporozygomatic branches of the facial nerve (a); Isolation of the mass above the zygomatic process (b); Cholesteatoma specimen $4 \times$ $6 \mathrm{~cm}$ mass was removed en bloc (c). 
this review.

\section{References}

[1] Tsai, C.J., Guo, Y.C., Tsai, T.L. and Shiao, A.S. (2003) Zygomatic Abscess Complicating a Huge Mastoid Cholesteatoma with Intacta Eardrum. Otolaryngology-Head and Neck Surgery, 198, 436-438. http://dx.doi.org/10.1067/mhn.2003.7

[2] Boulud, B., Costantini, J.L., Sprem, N. and Martin, H. (1976) Zygomatic-Temporal Pseudotumoral Type of Cholesteatoma. Apropos of 2 Cases. JFORL, 25, 561.

[3] Hossain, M.M., Kundu, S.C. and Haque, M.R., Shamsuzzaman, A.K., Khan, M.K. and Halder, K.K. (2006) Exctracranial Complications of Chronic Suppurative Otitis Media. Mymensingh Medical Journal, 15, 4-9.

[4] Baràth, K., Huber, A.M., Stampfli, P., Varga, Z. and Kollias, S. (2011) Neuroradiology of Cholesteatomas. American Journal of Neuroradiology, 32, 221-229. http://dx.doi.org/10.3174/ajnr.A2052

[5] Falcioni, M., Taibah, A., De Donato, G., Piccirillo, E., Caruso, A., Russo, A. and Sanna, M. (2002) Preoperative Imaging in Chronic Otitis Surgery. Acta Otorhinolaryngologica Italica, 22, 19-27. 
Scientific Research Publishing (SCIRP) is one of the largest Open Access journal publishers. It is currently publishing more than 200 open access, online, peer-reviewed journals covering a wide range of academic disciplines. SCIRP serves the worldwide academic communities and contributes to the progress and application of science with its publication.

Other selected journals from SCIRP are listed as below. Submit your manuscript to us via either submit@scirp.org or Online Submission Portal.
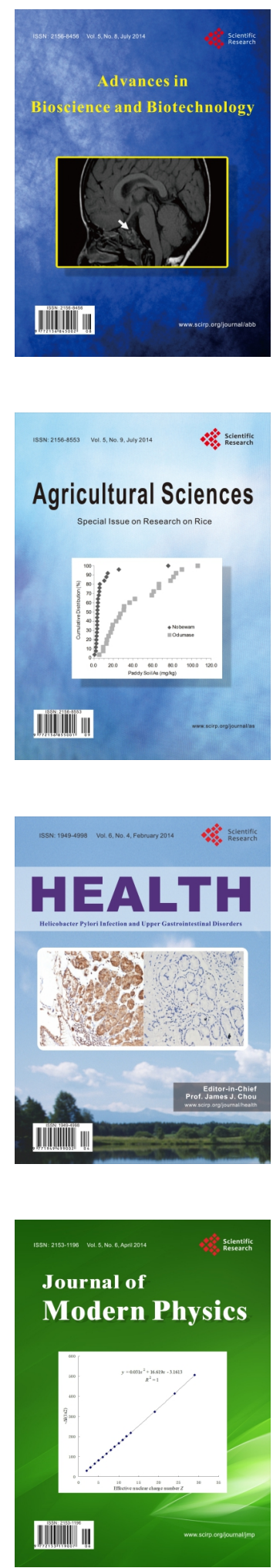
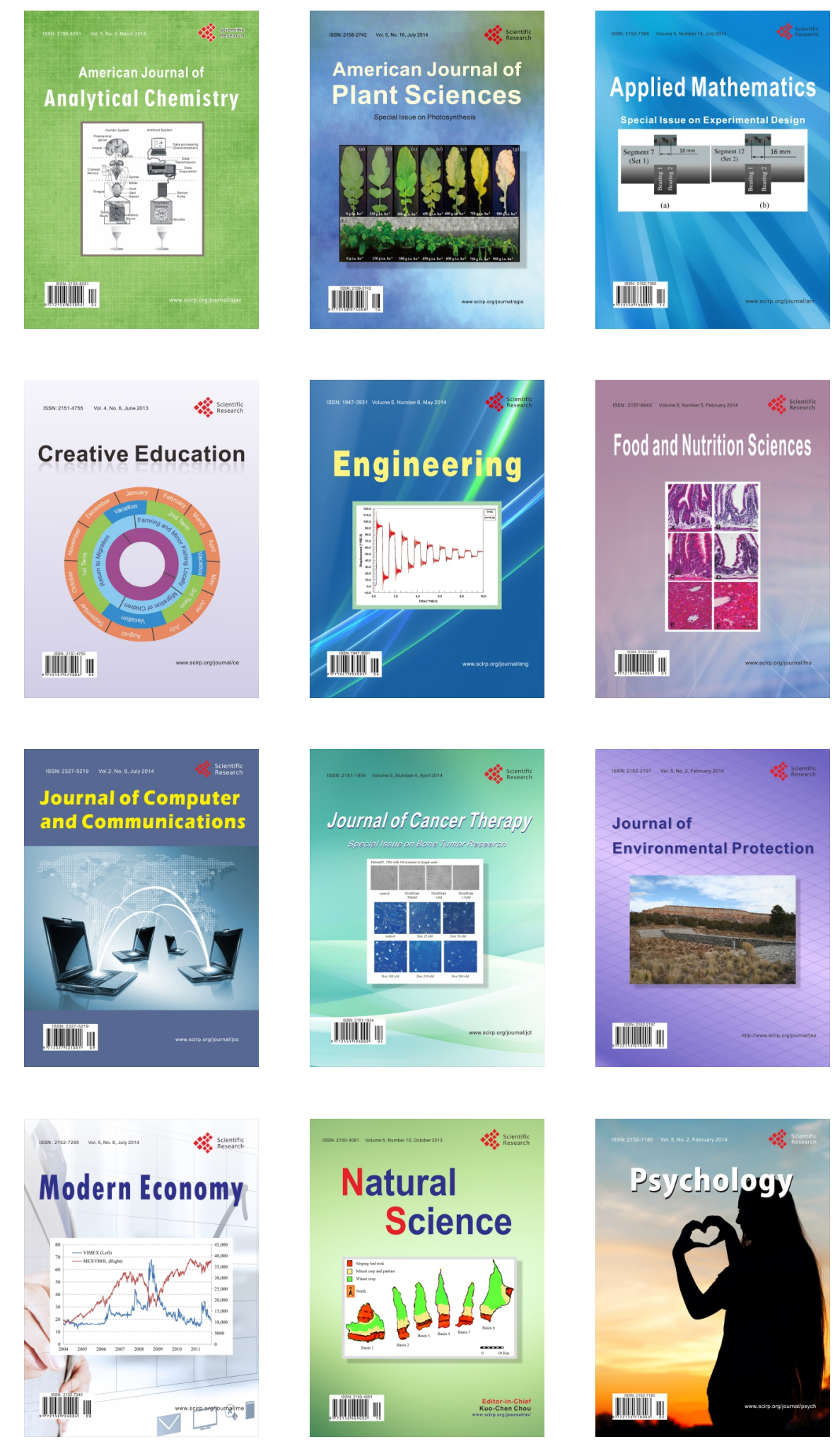